http://jmscr.igmpublication.org/home/ ISSN (e)-2347-176x ISSN (p) 2455-0450 crossref DOI: https://dx.doi.org/10.18535/jmscr/v8i3.14

Journal Of Medical Science And Clinical Research

\title{
Impact of Anaemia in Pregnancy on Feto-Maternal Outcome
}

\author{
Authors \\ Usharani A Devi ${ }^{1}$, Sushma HP*², L Ranjith Singh ${ }^{3}$, M Rameswar Singh ${ }^{4}$, \\ A Bidya Devi ${ }^{5}$, Florence Vanchhingpui ${ }^{6}$, Darshan $\mathrm{SM}^{7}$ \\ ${ }^{1,3,4}$ Professor, Department of Obstetrics and Gynaecology, Regional Institute of Medical sciences, Imphal, Manipur \\ ${ }^{2,5,6,7}$ Resident, Department of Obstetrics and Gynaecology, Regional Institute of Medical sciences, Imphal, Manipur \\ *Corresponding Author \\ Sushma HP
}

\begin{abstract}
Introduction: Anaemia is the most common and widespread nutritional disorder among pregnant women in the world - a global health concern. Prevalence of anaemia is highest in South Asian countries among the world. Among the South Asian countries, India has the highest prevalence of anaemia (70\%) and contributes to about $80 \%$ of the maternal deaths due to anaemia. Maternal haemoglobin has a positive relationship with the neonatal antropometric measurements. To plan effective intervention strategies to combat both iron deficiency and anaemia there is an urgent need to have better information on the iron status of populations that will enable the right interventions to be chosen in the first place and to make the journey of pregnancy safer.
\end{abstract}

Aims and Objectives: To determine the risk factors for anaemia in pregnancy and it's impact on maternal and foetal outcome.

Materials and Methods: A Cross sectional study conducted in the In-patient department of Obstetrics and Gynaecology, RIMS, Imphal, Manipur. Pregnant women with haemoglobin $<11 \mathrm{~g} / \mathrm{dl}$ who were admitted for delivery were included in the study after applying the inclusion and exclusion criteria. The study included 170 anaemic pregnant women who were classified into mild, moderate, severe and very severe anaemia according to ICMR guidelines. These patients were followed up from the time of admission to one week after delivery for maternal and perinatal outcome.

Results: The incidence of mild, moderate, severe anaemia and very severe anaemia were 48.8\%, 39.4\%, $10.6 \%, 1.2 \%$ respectively. Majority of the anaemic women belonged to low socioeconomic status $(88.82 \%)$ and rural area (84\%). $18.8 \%$ had maternal complications and fetal outcome were observed in terms of morbidity (59.4\%) and mortality (8.8\%).

Conclusion: Anaemia has an adverse effect on the pregnancy outcome affecting both the mother and the foetus. The improvement in the haemoglobin level of a pregnant woman will have a positive impact on fetomaternal outcome.

\section{Introduction}

Anaemia is the most common and widespread nutritional disorder among pregnant women in the world. It is the only nutrient deficiency which is also significantly prevalent in industrialised nation. WHO estimates the prevalence of anaemia for the year 2011 in pregnant women as 12 percent in developed countries and 50 percent in 
developing countries and 70 percent in India. ${ }^{1}$ The percentage of pregnant women with haemoglobin below $11 \mathrm{~g} / \mathrm{dl}$ in Manipur state is $36.7 \%{ }^{1}$

Over 30 percent ( 2 billion) of world's population are anaemic, many due to iron deficiency and in resource poor areas, this is frequently exacerbated by infectious diseases, malaria, HIV/AIDS, hookworm infestation, schistosomiasis and other infections such as tuberculosis are particularly important factors contributing to high prevalence of anaemia in some areas. Many studies reveal anaemia as the main cause of maternal morbidity and mortality. ${ }^{2}$

Prevalence of anaemia is highest in South Asian countries among the world. Among the South Asian countries, India has the highest prevalence of anaemia (70\%). India contributes to about 80 percent of the maternal deaths due to anaemia in South Asian countries. Five major surveysNational family Health Survey (NFHS) $-4^{3}$ Indian Council of Medical Research (ICMR) ${ }^{4}$ National Centre for Biotechnology Information(NCBI) ${ }^{5}$ District Level Household Survey (DLHS) ${ }^{6}$, National Nutrition Monitoring Bureau (NNMB) ${ }^{7}$ conducted a study to estimate prevalence of anaemia in the country and showed that over 70 percent of pregnant women and adolescents girls in the country were anaemic. Anaemia begins in childhood, worsens during adolescence and gets aggravated in pregnancy and childbirth. ${ }^{8}$

The National Nutritional Anaemia Control Programme (NNACP) was initiated in 1970 to provide free iron and folic acid supplementation to pregnant women commencing from second trimester to three months postpartum. The Healthcare and Research Association for Adolescents and Nutrition Foundation of India, New Delhi, studied and concluded that prevalence and severity of anaemia in rural pregnant women was $84 \%$ of which $9.2 \%$ were severely anaemic. ${ }^{9}$

To plan effective intervention strategies to combat both iron deficiency and anaemia there is an urgent need to have better information on the iron status of populations. This will enable the right interventions to be chosen in the first place and then, once programmes are in place, to have the right indicators to monitor their impact. Therefore the present study aims at finding out the sociodemographic factors associated with anaemia in pregnancy and also to know the impact of anaemia in pregnancy on feto-maternal outcome.

\section{Aims and Objects}

1. To determine the risk factors for anaemia in pregnancy

2. To determine the impact of anaemia in pregnancy on maternal and foetal outcome.

\section{Material and Methods}

Study Design: Cross sectional study

Study Setting: In patient department of Obstetrics and Gynaecology, Regional Institute of Medical Sciences, Imphal, Manipur

Study Duration: A two year study starting from July 2017 - Oct 2019

Study Population: Pregnant women with $\mathrm{Hb}<$ $11 \mathrm{~g} / \mathrm{dl}$ admitted to RIMS for delivery or reporting in antenatal clinic with symptoms of anaemia.

\section{Inclusion Criteria}

a) Pregnant women admitted for delivery and whose $\mathrm{Hb}<11 \mathrm{~g} / \mathrm{dl}$

b) Pregnant women of $>24$ weeks of gestation.

c) Patient willing to participate in the study.

\section{Exclusion Criteria}

a) Anaemia due to acute blood loss

b) Haemolytic anaemia

c) Women with past history of preterm

d) Other medical and obstetrical complication.

\section{Sample Size: 170}

Sample size calculated using the formula $(n)=z^{2}$ $\times \mathrm{p} \times \mathrm{q} / \mathrm{L}^{2}$

$\mathrm{P}$ is the incidence of low Apgar score at $1 \mathrm{~min}$ in babies born to anaemic mothers. ${ }^{10}$

$\mathrm{n}=169.62$; total sample size $\sim 170$

\section{Statistical Analysis}

Data was entered and analyzed using SPSS version 21.0 IBM for WINDOWS. Descriptive statistics such as frequency, percentage, mean and 
standard deviation were used. Chi-square/ Fisher Exact test has been used to find the significance of study parameters on categorical scale between two or more groups. P-value of $<0.05$ was considered as significant.

\section{Ethical Issues}

Ethical approval was obtained from the Research Ethics Board, RIMS, Imphal with reference number A/206/REB-Comm (SP)/RIMS /2015/ 354/97/2017.

\section{Results and Observation}

Table 1: Distribution of anemia according to age group $(\mathrm{n}=170)$

\begin{tabular}{|l|c|c|}
\hline Age in years & No. of patients & \% \\
\hline$<19$ & 9 & 5.2 \\
\hline $19-24$ & 44 & 25.8 \\
\hline $25-29$ & 47 & 27.6 \\
\hline $30-34$ & 40 & 23.5 \\
\hline$>35$ & 30 & 17.6 \\
\hline Total & 170 & 100.0 \\
\hline
\end{tabular}

The mean age of pregnant women with anemia were seen in the age group $25-34$ years $(27.6 \%)$ followed by $19-24$ years (25.8\%). Mean age of cases were 28.23 \pm 5.67 . Maximum and minimum age seen in the study was 42 years and 17 years respectively. Teenage pregnancy is seen in $5.2 \%$ of the cases.

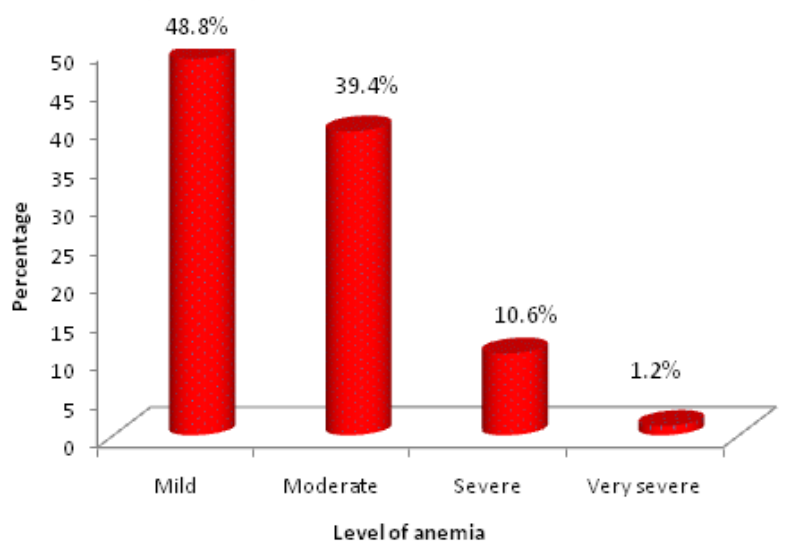

Figure 1: Bar diagram showing the distribution of patients according to severity of anaemia $(n=170)$

It was observed that nearly half of the cases (48.8\%) had mild anaemia, followed by moderate anaemia (39.4\%) and very few had severe anaemia $(10.6 \%)$ and very severe anaemia (1.2\%).
Table 2: Distribution of patients by their occupation $(\mathrm{n}=170)$

\begin{tabular}{|l|c|c|}
\hline Occupation & No. of patients & $\mathbf{\%}$ \\
\hline House wife & 142 & 83.5 \\
\hline Unskilled worker & 6 & 3.5 \\
\hline Semi professional & 6 & 3.5 \\
\hline Skilled worker & 6 & 3.5 \\
\hline Shop keeper & 2 & 1.8 \\
\hline Farm & 3 & 1.8 \\
\hline Professional & 2 & 1.2 \\
\hline Semi-skilled worker & 2 & 1.2 \\
\hline Total & 170 & 100.0 \\
\hline
\end{tabular}

Majority women were House wives (83.5\%), other occupations being semi professionals, skilled workers, farm/shop keeper, professional and semiskilled worker in the decreasing order.

Table 3: Distribution of patients by Religion $(\mathrm{n}=170)$

\begin{tabular}{|l|c|c|}
\hline Religion & No. of patients & \% \\
\hline Hindu & 87 & 51.2 \\
\hline Islam & 48 & 28.2 \\
\hline Christian & 35 & 20.6 \\
\hline Total & 170 & 100.0 \\
\hline
\end{tabular}

Majority of the anemic pregnant women belongs to Hindu religion $(51.2 \%)$, followed by Islamic (28.2\%) and Christian (35\%).

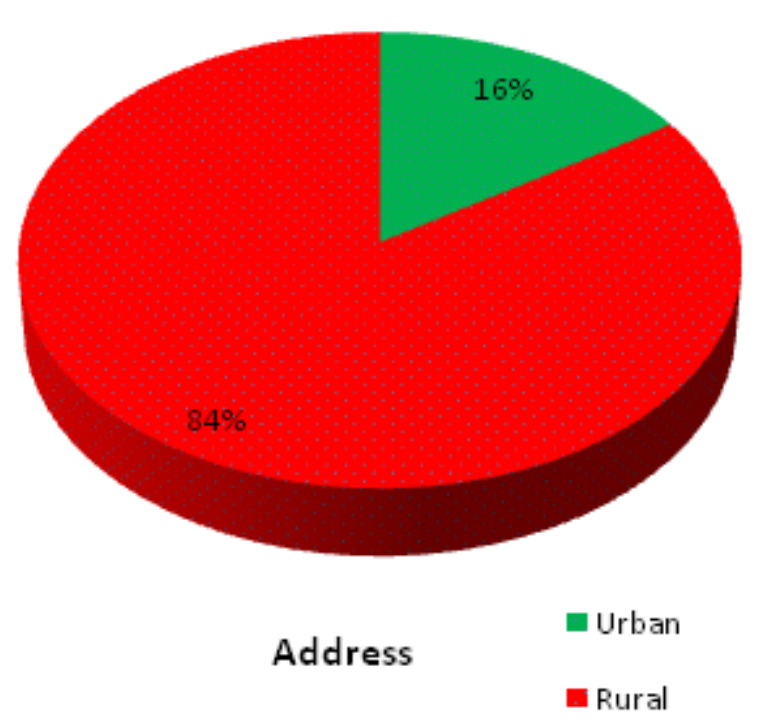

Figure 2: Pie chart showing the distribution of patients according to residence $(n=170)$

Majority of patients belonged to rural area (84\%) and very few belonged to urban $(16 \%)$ 


\section{JMSCR Vol||08||Issue||03||Page 83-93||March}

Table 4: Distribution of anemia according to educational Status $(n=170)$

\begin{tabular}{|l|c|c|}
\hline Educational Status & $\begin{array}{c}\text { No. of } \\
\text { patients }\end{array}$ & $\%$ \\
\hline Illiterate & 16 & 9.4 \\
\hline Primary school certificate & 1 & .6 \\
\hline Middle school certificate & 50 & 29.4 \\
\hline High school certificate & 71 & 41.8 \\
\hline $\begin{array}{l}\text { Intermediate/Post high } \\
\text { school Diploma }\end{array}$ & 17 & 10.0 \\
\hline Graduate & 11 & 6.5 \\
\hline Professional degree & 4 & 2.4 \\
\hline Total & 170 & 100.0 \\
\hline
\end{tabular}

Majority of the cases had education only till high school (41.8\%), followed by Middle school (29.4\%), intermediate/post high school diploma (10\%). Out of 170 cases, 16 cases were illiterate (9.4\%), 1 had education only till middle school $(0.6 \%)$ and only 11 cases were graduates $(6.5 \%)$ and 4 professional degree $(2.4 \%)$.

Table 5: Distribution of anemia according to socioeconomic status $(n=170)$

\begin{tabular}{|l|c|c|}
\hline Socio-economic status & No. of patients & \% \\
\hline Upper & 3 & 1.8 \\
\hline Upper middle & 16 & 9.4 \\
\hline Lower middle & 106 & 62.4 \\
\hline Upper lower & 40 & 23.5 \\
\hline Lower & 5 & 2.9 \\
\hline Total & 170 & 100.0 \\
\hline
\end{tabular}

Majority of the patients belonged to lower socioeconomic status (88.82\%), which was further classified as lower middle (62.4\%), upper lower $(40 \%)$ and lower $(2.9 \%)$ class according to modified Kuppuswamy's classification.

Table 6: Distribution of anemia according to IFA supplementation $(n=170)$

\begin{tabular}{|l|l|l|}
\hline IFA Supplementation & No. of patients & \% \\
\hline No & 19 & 11.2 \\
\hline Regular & 108 & 63.5 \\
\hline Irregular & 43 & 25.3 \\
\hline Total & 170 & 100.0 \\
\hline
\end{tabular}

Less than three fourth of the patients had regular iron and folic acid intake and $11.2 \%$ had not taken any iron and folic acid tablets.

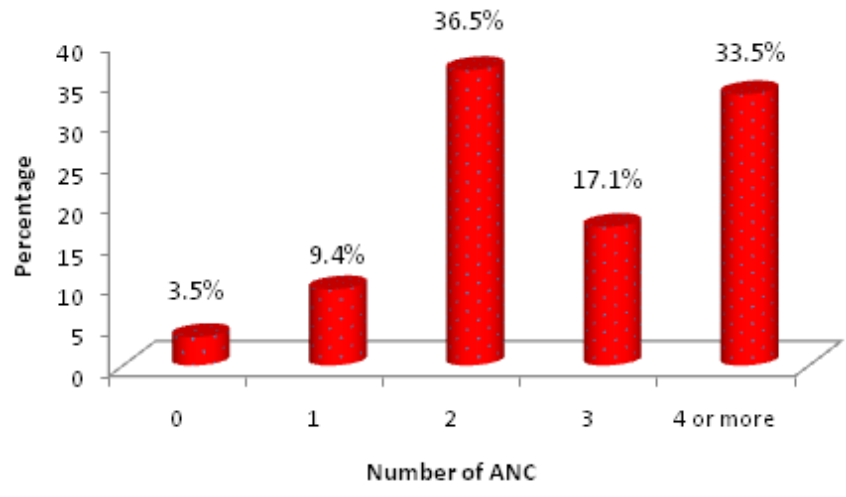

Figure 3: Bar diagram showing the distribution of anemia according to number of antenatal visits $(\mathrm{n}=170)$

In the study it was observed that only quarter (33.5\%) of the patients had adequate antenatal checkups (4 or more). Remaining cases had inadequate antenatal check up, out of which 6 patients had zero antenatal visits and majority had only two antenatal visits (36.5\%).

Table 7: Distribution of patients according to parity $(\mathrm{n}=170)$

\begin{tabular}{|l|c|c|}
\hline Parity & No. of patients & \% \\
\hline Primi & 44 & 25.9 \\
\hline Multi & 91 & 53.5 \\
\hline Grand Multi & 35 & 20.6 \\
\hline Total & 170 & 100.0 \\
\hline
\end{tabular}

In this study it was observed that majority of the anemic pregnant women were multipara $(53.5 \%)$ followed by primigravida (25.9\%). $20.6 \%$ of cases had more than three living issues (grand multipara)

Table 8: Distribution according to type of anemia $(\mathrm{n}=170)$

\begin{tabular}{|l|c|c|}
\hline Type of anemia & No. of patients & \% \\
\hline Normocytic normochromic & 38 & 22.4 \\
\hline Microcytic hypochromic & 128 & 75.3 \\
\hline Dimorphic anemia & 4 & 2.4 \\
\hline Total & 170 & 100.0 \\
\hline
\end{tabular}

Peripheral smear showed Microcytic hypochromic anemia in majority of the cases $(75.3 \%)$ followed by normocytic normochromic anemia (22.4\%). Dimorphic anemia was seen only in 4 cases $(2.4 \%)$ and megalobastic anemia was not evident. 


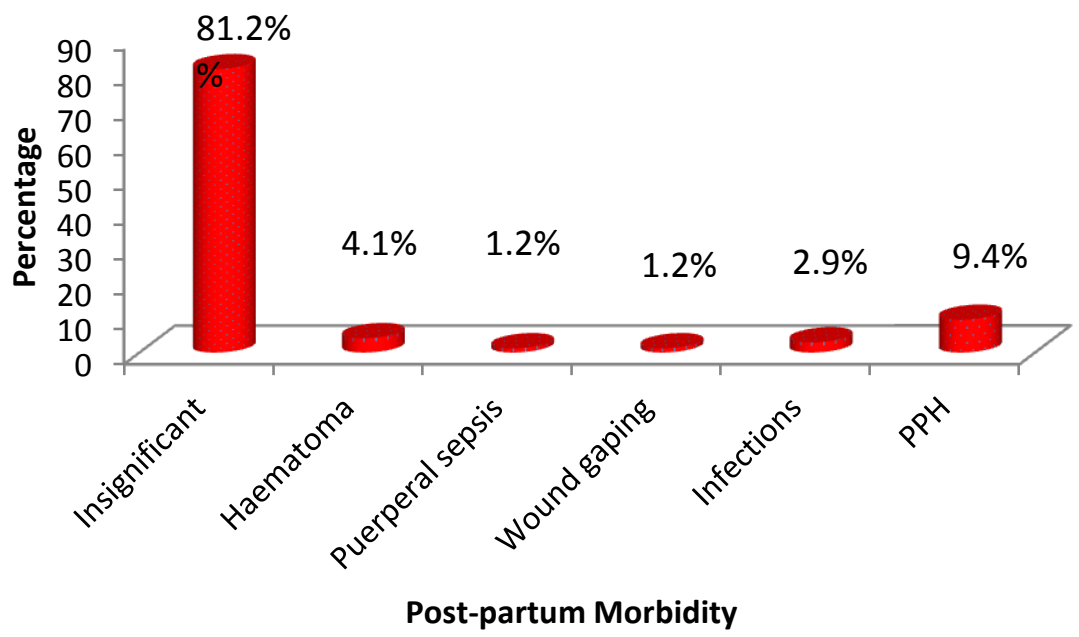

Figure 4: Bar diagram showing distribution of patients according to maternal outcome $(n=170)$

It is observed that a maternal complication like hematoma is seen in $2.4 \%$ of mild anaemic cases, $4.5 \%$ of moderate anaemic cases and $11.1 \%$ of severe anaemic cases; puerperal sepsis is seen in $1.2 \%$ of mild anaemic cases and $1.5 \%$ of moderate anaemic cases; postpartum infections are seen in $6 \%$ of moderate anaemia and $5.6 \%$ of severely anaemic cases; $\mathrm{PPH}$ was observed in $2.4 \%$ of mild anaemic cases, $16.4 \%$ of moderate anaemic cases, $11.1 \%$ of severely anaemic cases. Spontaneous preterm was observed in $4.8 \%$ of mild anaemic cases, $23.9 \%$ of moderate anaemic cases, $33.3 \%$ of severely anaemic cases and $50 \%$ of very severely anaemic cases.

Table 9: Outcome variables association with levels of anemia of patients studied $(n=170)$

\begin{tabular}{|c|c|c|c|c|c|c|}
\hline \multirow[b]{2}{*}{ Variables } & \multicolumn{4}{|c|}{ Level of anemia } & \multirow[b]{2}{*}{$\begin{array}{c}\text { Total } \\
(n=170)\end{array}$} & \multirow[b]{2}{*}{$P$ value } \\
\hline & $\begin{array}{c}\text { Mild } \\
(\mathrm{n}=83)\end{array}$ & $\begin{array}{c}\text { Moderate } \\
(n=67)\end{array}$ & $\begin{array}{l}\text { Severe } \\
(n=18)\end{array}$ & $\begin{array}{c}\text { Very Severe } \\
(\mathbf{n}=\mathbf{2})\end{array}$ & & \\
\hline \multicolumn{7}{|l|}{ Mode of Delivery } \\
\hline Vaginal & $51(61.4 \%)$ & $38(56.7 \%)$ & $10(55.6 \%)$ & $1(50 \%)$ & $100(58.8 \%)$ & \multirow{3}{*}{0.634} \\
\hline Operative vaginal & $6(7.2 \%)$ & $11(16.4 \%)$ & $2(11.1 \%)$ & $0(0 \%)$ & $19(11.2 \%)$ & \\
\hline LSCS & $26(31.3 \%)$ & $18(26.9 \%)$ & $6(33.3 \%)$ & $1(50 \%)$ & $51(30 \%)$ & \\
\hline \multicolumn{7}{|c|}{ Antepartum infections } \\
\hline Yes & $6(7.2 \%)$ & $23(34.3 \%)$ & $5(27.8 \%)$ & $1(50 \%)$ & $35(20.6 \%)$ & \multirow{2}{*}{$<0.001 * *$} \\
\hline No & $77(92.8 \%)$ & $44(65.7 \%)$ & $13(72.2 \%)$ & $1(50 \%)$ & $135(79.4 \%)$ & \\
\hline \multicolumn{7}{|c|}{ Post-partum morbidity } \\
\hline Insignificant & $77(92.8 \%)$ & $47(70.1 \%)$ & $13(72.2 \%)$ & $1(50 \%)$ & $138(81.2 \%)$ & \multirow{6}{*}{$0.006 * *$} \\
\hline Hematoma & $2(2.4 \%)$ & $3(4.5 \%)$ & $2(11.1 \%)$ & $0(0 \%)$ & $7(4.1 \%)$ & \\
\hline Puerperal pyrexia & $1(1.2 \%)$ & $1(1.5 \%)$ & $0(0 \%)$ & $0(0 \%)$ & $2(1.2 \%)$ & \\
\hline Wound gaping & $1(1.2 \%)$ & $1(1.5 \%)$ & $0(0 \%)$ & $0(0 \%)$ & $2(1.2 \%)$ & \\
\hline Infections & $0(0 \%)$ & $4(6 \%)$ & $1(5.6 \%)$ & $0(0 \%)$ & $5(2.9 \%)$ & \\
\hline $\mathrm{PPH}$ & $2(2.4 \%)$ & $11(16.4 \%)$ & $2(11.1 \%)$ & $1(50 \%)$ & $16(9.4 \%)$ & \\
\hline \multicolumn{7}{|l|}{ Obstetric outcome } \\
\hline Pre-term & $4(4.8 \%)$ & $16(23.9 \%)$ & $6(33.3 \%)$ & $1(50 \%)$ & $27(15.8 \%)$ & \multirow{2}{*}{$<0.001 * *$} \\
\hline Term & $79(95.2 \%)$ & $51(76.1 \%)$ & $12(66.7 \%)$ & $1(50 \%)$ & $143(84.1 \%)$ & \\
\hline
\end{tabular}

In this study, it was observed that one third $(32.5 \%)$ of mild anaemic cases, $74.6 \%$ of moderate anaemic cases, majority of severe anaemic cases $(94.4 \%)$ and all cases $(100 \%)$ of very severe anaemia were unbooked.
It is also observed that less than a quarter (27.7\%) cases of mild anaemic cases, $28 \%$ of moderate anaemic cases, a quarter $(33.3 \%)$ cases of severe anaemic cases and half (50\%) of very severely anaemic cases had inadequate birth spacing. 
It is analysed that the incidence of operative vaginal delivery and LSCS in anaemic pregnant women is increased. $31.3 \%$ and $7.2 \%$ cases of mild anaemia, $26.9 \%$ and $16.4 \%$ cases of moderate anaemia, $33.3 \%$ and $11.1 \%$ of severely anaemic cases and half (50\%) of very severely anaemic cases had LSCS and operative vaginal deliveries respectively.

Foetal complications observed were Prematurity, low birth weight, fetal growth restriction, IUD, neonatal mortality and low Apgar score.

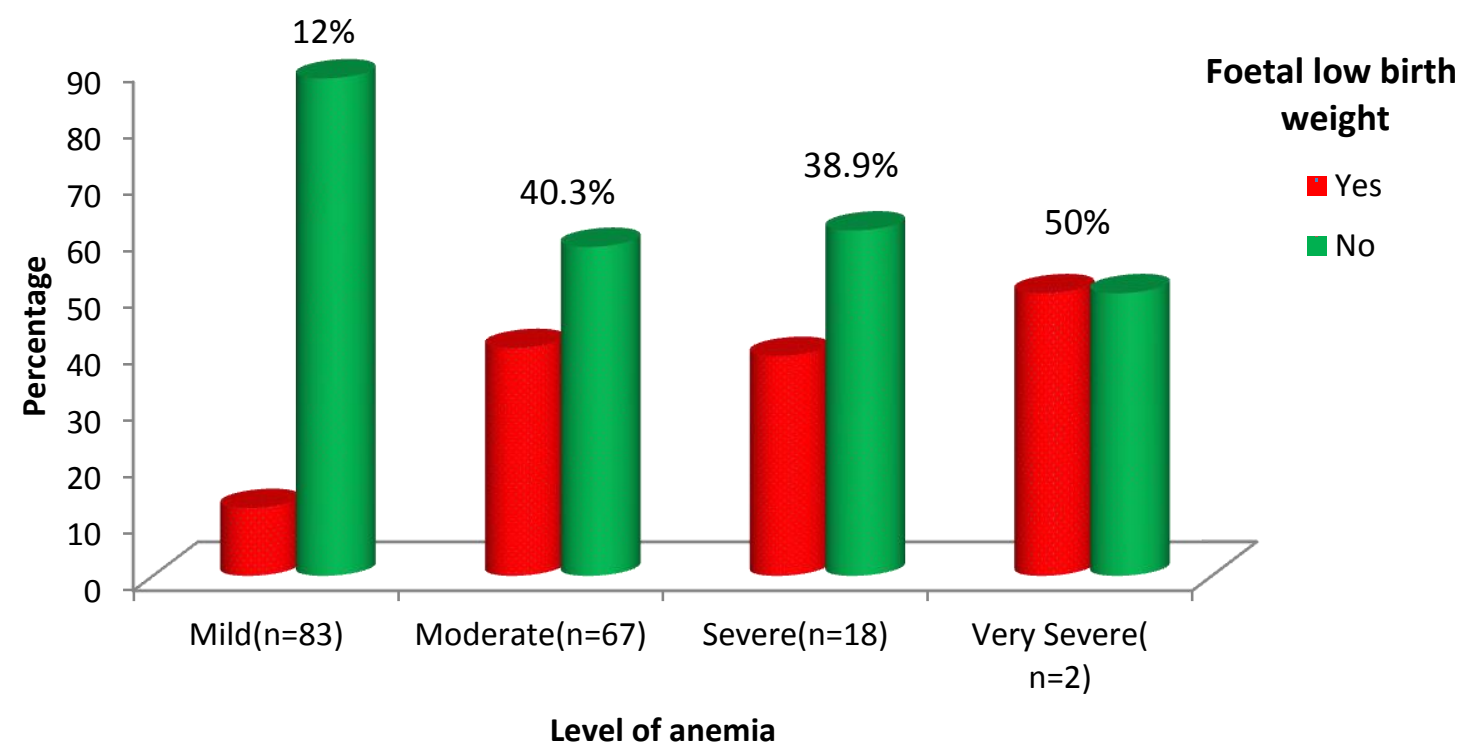

Figure 5: Bar diagram showing distribution of low birth weight babies according to severity of anaemia $(n=170)$

Low birth weight babies were observed in $12 \%$ of mild anaemic cases, $40.3 \%$ of moderate anaemic cases, $38.9 \%$ of severe anaemic cases and $50 \%$ of very severe anaemic cases.

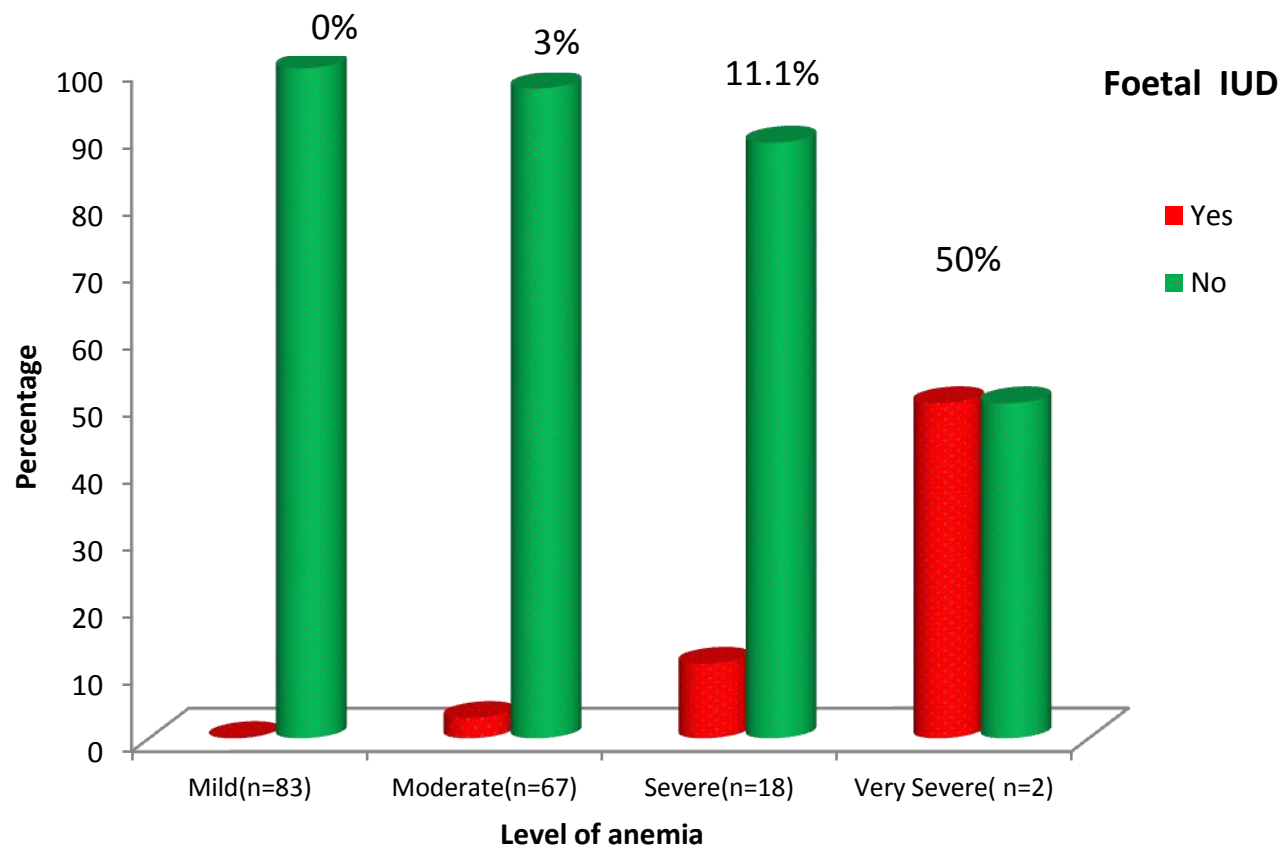

Figure 6: Bar diagram showing distribution of intrauterine death according to severity of anaemia $(\mathrm{n}=170)$ No IUD was seen in pregnant women with mild anaemia, $3 \%$ of cases with moderate anaemia, $11.1 \%$ of cases with severe anaemia and $50 \%$ of cases with very severe anaemia had IUD. 


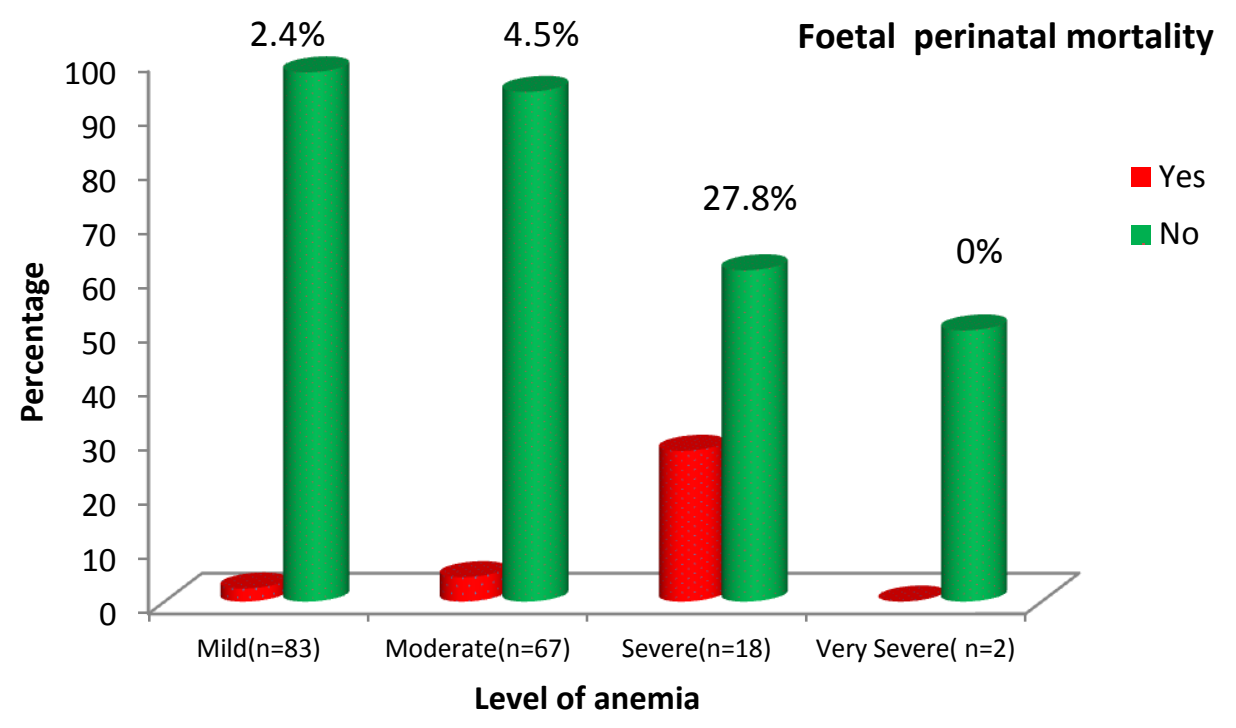

Figure 7: Distribution of perinatal mortality according to severity of anaemia $(n=170)$

Perinatal mortality was seen $2.4 \%$ cases of mild anaemia, $4.5 \%$ cases of moderate anaemia and $27.8 \%$ cases of severe anaemia.

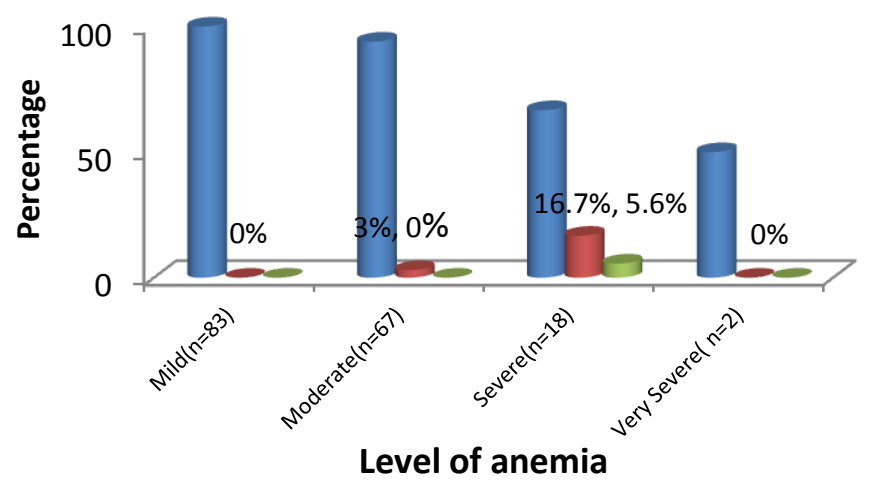

\section{Apgar 5mins}

- No depression

- Mild depression

- Severe depression

Figure 8: Bar diagram showing distribution of low Apgar score according to severity of anaemia $(n=170)$ Apgar score at $5 \mathrm{~min}<7$ was seen in $3 \%$ of moderate anaemic cases and $12.1 \%$ of severe anaemic cases.

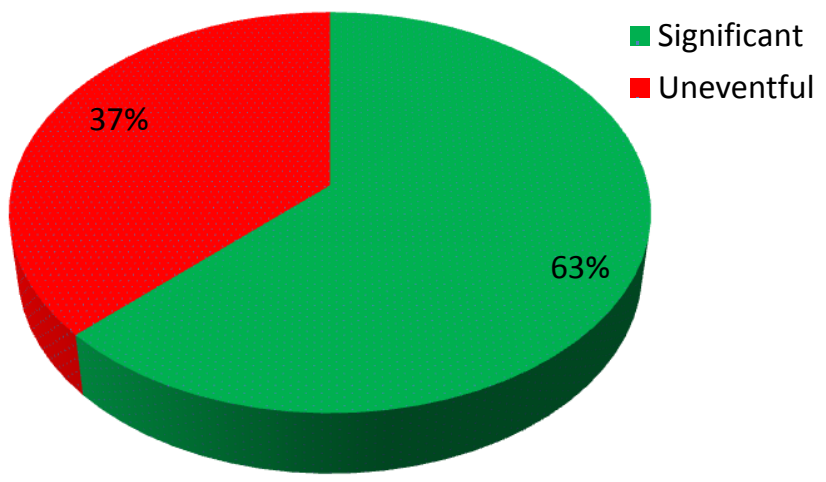

Figure 9: Pie chart showing distribution of feto-maternal outcome in pregnancy with anaemia $(\mathrm{n}=170)$

Hence in present study, it was observed that adverse feto-maternal outcome was seen maximum in pregnant women with anaemia $(63 \%)$ 


\section{Discussion}

In the present study 170 anaemic pregnant women admitted in ward were studied. These women were classified into mild, moderate, severe and very severe group according to ICMR guideline and aimed at studying the risk factors predisposing pregnant women of Manipur to anaemia and to analyse the feto-maternal outcome in different grades of anaemia in pregnancy.

The various parameters of the cases were studied, analysed and evaluated with the standard literatures available.

In the present study $48.8 \%$ had mild anaemia, $39.4 \%$ had moderate anaemia, $10.6 \%$ had severe anaemia and $1.2 \%$ had very severe anaemia. The prevalence of varying degree of anaemia in the present study is consistent with the study of Stephen $\mathrm{G}$ et $\mathrm{al}^{11}$ which showed $42.1 \%$ mothers had mild anaemia, $45.2 \%$ had moderate anaemia and $12.6 \%$ had severe anaemia.

In the present study the mean age of pregnant women with anaemia was found to be $28.23 \pm 5.67$ where majority of cases belonged to the age group of 25-29 (27.6\%) years followed by 19-24 years (25.8\%) and 30-34 years (23.5\%), whereas in a study by Maka SS et $\mathrm{al}^{13}$ the mean age of pregnant women was $22.4 \%$ and in a study by Upadhyay C et $\mathrm{al}^{8}$, it was observed that majority of the anaemic study subjects belonged to the age group of 20-24 years $(46.5 \%)$. However the mean age group of pregnant women with anaemia was found to be statistically significant in the present study. In the present study it is found that anaemia is almost equally distributed between 20 years to 35 years.

In the present study it was observed that majority of the pregnant women with anaemia are housewives $(83.5 \%)$ and had only up to high school certificate $(41.8 \%)$ followed by middle school certificate (29.4\%) and illiteracy (9.4\%). These results were found to be consistent with the study by Tomar GS et $\mathrm{al}^{14}$ showing that the prevalence of anaemia was relatively more in housewives $(86.4 \%)$, in those who studied up to secondary level $(89.3 \%)$, having vegetarian diet $(86.8 \%)$. However in the present study all cases found to have mixed diet as in Manipur majority consumes mixed diet.

In the present study majority of the pregnant women with anaemia belong to rural area $(84.1 \%)$ and lower socioeconomic status $(88.8 \%)$ of which $62.4 \%$ belongs to lower middle, $23.8 \%$ belongs to upper lower and $2.9 \%$ belongs to lower class of socioeconomic status. This result is consistent with a study by Biswas $\mathrm{M}$ et $\mathrm{al}^{15}$ that showed the higher prevalence of anaemia in lower socioeconomic group (74.37\%). Out of 170 patients, $51.2 \%$ were Hindus, $28.1 \%$ belonged to Islamic religion and $20.6 \%$ were Christians. These findings were consistent with the results of study by Khan MS et al ${ }^{16}$ that showed the majority of studied patients were Hindus (51.2\%) followed by Islam (28.1\%) and Christian (20.6\%). Majority of the cases were multipara $(53.5 \%)$ and grand multipara $(20.6 \%)$ whereas primigravida constituted only $25.9 \%$. These results are consistent with the results of study conducted by Tusimin $\mathrm{M}$ et $\mathrm{al}^{17}$ that showed the prevalence of anaemia was more in multipara $(61 \%)$. Severe and very severe anaemia were more common among grand multipara. It was also observed that only $33.5 \%$ of cases had adequate antenatal checkups and $63.5 \%$ cases had regular IFA tablets intake. There were zero antenatal visits in $3.5 \%$ cases, $66.5 \%$ had inadequate antenatal visit. It was observed that $11.2 \%$ cases had no IFA tablet intake and $22.3 \%$ had taken IFA for less than two to three months in the entire duration of pregnancy. So, a total of $33.5 \%$ cases had regular IFA tablets intake. These findings are consistent with the results of study by Stephen $\mathrm{G}$ et $\mathrm{al}^{11}$ showing that only $31.1 \%$ cases had adequate antenatal check up and $44.7 \%$ had consumed IFA tablets for less than two months. It is observed that only $42.9 \%$ of cases were booked and $48.2 \%$ had history of abortion. These findings are consistent with Upadhyay et $\mathrm{al}^{8}$ where $53 \%$ of booked cases were seen. Microcytic hypochromic (75.3\%) and normocytic normochromic (22.4\%) type of blood picture was predominantly seen suggesting that pregnant women are more prone 
for iron deficiency anaemia. This observation was consistent with the result of Maka SS et $\mathrm{al}^{13}$ in which majority had microcytic hypochromic type of blood picture (82\%).

In the present study the anaemic women underwent LSCS were $30 \%$ whereas in a study by Suryanarayanan $\mathrm{R}$ et $\mathrm{al}^{12}$, it was showed that prevalence of LSCS was more in anaemic women (60\%). In this study, the association between anaemia and LSCS was statistically not significant and it might be a spurious association as the study was done in a tertiary centre where cases are received in the last stage and also due to logistic constraints.

In the present study, $18.8 \%$ of maternal morbidity was observed which constituted of $\mathrm{PPH}(9 \%)$, wound dehiscence $(1.2 \%)$, postpartum pyrexia $(1.2 \%)$, haematoma $(4.1 \%)$ and infections $(2.9 \%)$. However there was no maternal mortality in the study. These results are consistent with a study conducted by Singal et al ${ }^{18}$ which showed that the maternal morbidity associate with anaemia in pregnancy was $14.5 \%$ that constituted $\mathrm{PPH}$ (7.5\%), wound dehiscence $(0.5 \%)$, postpartum pyrexia $(1.2 \%)$, respiratory infections $(1.5 \%)$, failed lactation $(1.5 \%), \mathrm{CCF}(1.5 \%)$ and retained placenta $(1.5 \%)$. Maka SS et al ${ }^{13}$ showed that the incidence of maternal morbidity in pregnancies with anaemia was $16 \%$ which was constituted of PPH (4\%), Postpartum pyrexia (9\%), Sepsis (2\%) and CCF (1\%).

In the present study, foetal outcome was observed in terms of fetal morbidity and mortality. It was observed that $15.3 \%$ were premature babies, $26.5 \%$ were low birth weight (LBW), $14.1 \%$ had foetal growth restriction, $2.9 \%$ had intrauterine death (IUD), $5.9 \%$ had perinatal mortality and $3.5 \%$ had Apgar score at 5 minutes $<7$. These results were consistent with the results of studies by Maka SS et $\mathrm{al}^{13}$ that showed the foetal complications in terms of preterm (20\%), IUGR $(28 \%)$ and IUD (3\%). A study by Ghimire $\mathrm{RH}^{19}$ et al showed that the incidence of IUD was $6 \%$, LBW was 22\% and low Apgar score at 5 minutes was $18 \%$. In a study by Upadhyay et al $^{8}$ there were $20 \%$ preterm babies, 28\% IUGR and 3\% IUD.

However all the maternal and foetal outcomes in the present study were found to be statistically significant.

\section{Limitation of Present Study}

Sample size of the study could have been larger, however due to the constraints of time and logistics this was not feasible.

\section{Conclusion}

The present study clearly revealed that anaemia is more common among pregnant women who had poor antenatal care with irregular intake of Iron and Folic acid during pregnancy. Among anaemic pregnant women only one third had four or more antenatal visits. Out of 170 women, 2 women had very severe anaemia in whom maternal and foetal outcome was compromised. The maternal and foetal morbidity were directly proportional to the severity of anaemia.

It was observed that there was a statistically significant association between sociodemographic factors and frequency of anaemia. Anaemia is more common among pregnant women who belonged to rural household as they have poor access to antenatal care. Low socioeconomic status, iliteracy, multiparity, women with history of abortion, women with suboptimal antenatal care and poor compliance to IFA tablets intake were more susceptible for anaemia during pregnancy.

This study also revealed that anaemia has an adverse effect on the pregnancy outcome affecting both the mother and the foetus. Maternal morbidities in the form of PPH, haematoma, wound dehiscence, sepsis and puerperal pyrexia were more common in anaemic pregnant women. Babies born to anaemic mothers have more frequent complications of IUD, LBW and prematurity along with its attendant complications leading to increased perinatal morbidity and mortality. 
It can be inferred that better access to health care facilities, adequate antenatal care, regular IFA intake, lower birth order and use of family planning methods can significantly reduce the risk of anaemia in pregnancy. The improvement in the haemoglobin level of a pregnant woman will have a positive impact on feto-maternal outcome.

\section{References}

1. WHO. Global prevalence of anaemia in 2011. Available at: www.who.int/vmnis. Accessed on August 8th, 2017.

2. WHO. Micronutrient deficiency: Battling iron deficiency anaemia, the challenge in 2011. Available at: URL: http://www.who.int/nutrition/topics/ida/en. Accessed on July $15^{\text {th }}, 2017$.

3. IIPS. National Family Health Survey 2015-16 (NFHS-4): Available at: URL:http://rchiips.org/nfhs/NFHS-

4Report.shtml.Accessed on September $20^{\text {th }}, 2019$.

4. Toteja GS, Singh P. Micronutrient profile of Indian children and women. Indian pediatr 2003;40(5):477-9.

5. Idowu OA, Mafiana CF, Dapo S. A survey of anaemia in pregnant women in Abeokuta, Nigeria. Afr Health Sci 2005 April;5(4):295-9.

6. DLHS on RCH. Nutritional status of children and prevalence of anaemia among children, Adolescent girls and pregnant women 2002-2004. Available at: URL: http://www.rchindia.org/nr_india.html. Accessed on $15^{\text {th }}$ June 2017.

7. National Nutrition Monitoring Bureau (NNMB) 1975-2006. NNMB Reports. National Institute of Nutrition, Hyderabad. Available at: URL: http://www.numbindia.org/downloads.htm 1. Accessed on 12th July 2017.

8. Upadhyay C, Bulusu R, Shah N. A prospective study on prevalence and management of anaemia in pregnancy with perinatal outcome. J Evol Med Dent Sci 2013;2(35):6664-72.

9. FOGSI General Clinical Practice Recommendations Management of Iron Deficiency Anemia in Pregnancy. Available at: URL:

https://www.fogsi.org/wpcontent/uploads/2017/07/gcprrecommendation-ida.pdf. Accessed on 20th September 2019.

10. Marahatta R. Anaemia in pregnancy and its outcome. Nepal Med Coll J 2007;9(4):270-4

11. Stephen G, Mgongo M, Hashim T, Katanga J, Pedersen BS, Msuya SE. Anaemia in pregnancy: prevalence, risk factors and adverse perinatal outcomes in Northern Tanzania. Available at: URL:https://www.ncbi.nlm.nih.gov/pubme d/29854446. Accessed on 7th September 2019.

12. Suryanarayan R, Chandrappa M, Santhuram AN, Pratima S, Sheela SR. Prospective study on prevalence of anaemia in pregnant women and its outcome: A community based study. J Family Med Prim Care 2017;6(4):739-43.

13. Maka SS, Tondare SB, Tondare MB. Study of impact of anemia on pregnancy. Int J Reprod Contacept Obstet Gynecol 2017;6(11):4847-50.

14. Tomar GS, Singhal S, Shukla A. Anemia in pregnancy: Epidemiology and it's determinants. Int J Med Health Research 2017;3(1):05-09.

15. Biswas M, Baruah R. Maternal anaemia associated with socio-demographic factors among pregnant women of Boko-Bongaon Block Kamrup, Assam. IJBMR 2013;3 (2):712-21.

16. Khan MS, Srivastav A, Dixit AK. The burden of anaemia amongst antenatal women in the rural population of Northern India. Int J Sci Study 2014;1(4):40-2. 
17. Tusimin M, Yazit A, Zainulddin NS, Vaippuri VS, Noor MS. The impact of severity of antenatal anaemia on maternal and perinatal outcome in Hospital Serdang, Central Malaysia. J Preg Child Health 2016;3(121):126-32.

18. Singal N, Setia G, Taneja K, Singal KK. Factors associated with maternal anaemia among pregnant women in rural India. Bangladesh J Med Sci 2018;17(4): 583-592.

19. Ghimire R, Ghimire S. Maternal And Fetal Outcome Following Severe Anaemia In Pregnancy: Results From Nobel Medical College Teaching Hospital, Biratnagar, Nepal. JoNMC 2013;2(1):22-6. 